\title{
Perceptions of Stroke and Associated Health-Care-Seeking Behavior in Northern Tanzania: A Community-Based Study
}

\author{
Julian T. Hertz ${ }^{\mathrm{a}}$ Deng B. Madut ${ }^{\mathrm{b}}$ Gwamaka William $^{\mathrm{c}}$ Venance P. Maro ${ }^{\mathrm{d}}$ \\ John A. Crump ${ }^{\text {e }}$ Matthew P. Rubach ${ }^{\text {b }}$ \\ ${ }^{a}$ Division of Emergency Medicine, Duke University Medical Center, Durham, NC, USA; ${ }^{b}$ Department of Medicine, \\ Duke University Medical Center, Durham, NC, USA; 'Kilimanjaro Christian Medical Centre, Moshi, Tanzania; \\ ${ }^{\mathrm{d}}$ Department of Medicine, Kilimanjaro Christian Medical Centre, Moshi, Tanzania; ${ }^{\mathrm{e} O t a g o}$ Global Health Institute, \\ University of Otago, Dunedin, New Zealand
}

\section{Keywords}

Stroke · Sub-Saharan Africa · Knowledge ·

Health-care-seeking behavior - Tanzania

\begin{abstract}
Background: Little is known about knowledge of stroke symptoms, perceptions of self-risk, and health-care-seeking behavior for stroke in East Africa. Methods: A 2-stage randomized population-based cluster survey with selection proportional to population size was performed in northern Tanzania. Self-identified household health-care decision makers were asked to list all symptoms of a stroke. They were further asked if they thought they had a chance of having a stroke and where they would present for care for stroke-like symptoms. A socioeconomic status score was derived via
\end{abstract}

\section{KARGER}

E-Mail karger@karger.com www.karger.com/ned
(C) 2019 The Author(s) Published by S. Karger AG, Basel

Karger

0 pen access

This article is licensed under the Creative Commons Attribution 4.0 International License (CC BY) (http://www.karger.com/Services/ OpenAccessLicense). Usage, derivative works and distribution are permitted provided that proper credit is given to the author and the original publisher. principal component analysis from 9 variables related to wealth. Results: Of 670 respondents, 184 (27.4\%) knew a conventional stroke symptom and 51 (7.6\%) thought they had a chance of having a stroke. Females were less likely to perceive themselves to be at risk than males (OR 0.49, 95\% $\mathrm{Cl} 0.28-0.89, p=0.014)$. Of respondents, $558(88.3 \%)$ stated they would present to a hospital for stroke-like symptoms. Preference for a hospital was not associated with knowledge of stroke symptoms or perception of self-risk but was associated with a higher socioeconomic status score $(p<0.001)$. Conclusions: Knowledge of stroke symptoms and perception of self-risk are low in northern Tanzania, but most residents would present to a hospital for stroke-like symptoms.

C 2019 The Author(s)

Published by S. Karger AG, Basel
Dr. Julian T. Hertz, MD

Division of Emergency Medicine, Duke Global Health Institute Duke University Medical Center, Box 102359

Durham, NC 27710 (USA)

E-Mail julian.hertz@ duke.edu 


\section{Introduction}

Stroke is a life-threatening emergency and a leading cause of death and disability worldwide [1]. Stroke disproportionately affects persons living in low- and middleincome countries, where the majority of stroke-related disability and stroke mortality occur [2]. In sub-Saharan Africa (SSA), the burden of stroke is substantial and growing [3-6], and limited existing data suggest that the incidence of stroke in many parts of SSA is higher than in high-income countries [2]. The estimated incidence of stroke in Tanzania, for example, is among the highest in the world with an annual 109-316 strokes per 100,000 persons $[7,8]$.

Given the growing burden of disease, there has been increasing study of community knowledge of stroke symptoms in SSA. Such research has been conducted mostly in West Africa, where between 33 and $98 \%$ of respondents could identify at least one stroke symptom [916]. Very little study has been done of stroke symptom awareness in East Africa, despite evidence that the incidence of stroke is higher in East than West Africa [2, 7]. The only existing data regarding knowledge of stroke symptoms in East Africa come from Uganda, where 25$43 \%$ of participants knew a stroke symptom $[17,18]$. In Tanzania, to our knowledge, there has been no study to date of community awareness of stroke symptoms.

Little is known about health-care-seeking behavior for stroke and perception of self-risk of stroke in SSA. In Ghana, Nigeria, and Uganda, between 61 and 85\% of respondents reported that they would present to a hospital if they thought they were having a stroke $[10,11,17]$, but there are no other data about patterns of care seeking for stroke across SSA. With regard to perception of self-risk, only $66 \%$ of participants in a single study in Uganda thought they were at risk of suffering a stroke [17], but to our knowledge, no other study of perceptions of self-risk has been done in SSA.

Developing a greater understanding of stroke symptom knowledge, perception of self-risk, and health-careseeking behavior in SSA is needed to identify knowledge gaps, describe current patterns of care seeking, and develop educational interventions regarding stroke. In high-income settings, earlier presentation to hospital and earlier treatment of stroke result in better long-term neurologic outcomes [19], but it is unknown if prompt hospital presentation for stroke improves morbidity or mortality in SSA. Thus, understanding patterns of care seeking for stroke in SSA and the way such behavior is influenced by stroke symptom knowledge and perception of self-risk may be important in designing educational programs to stem the rising tide of stroke-related mortality and disability across SSA.

We sought to describe knowledge of stroke symptoms, perception of self-risk, health-care-seeking behavior for stroke-like symptoms, and the interaction between these factors in Tanzania. To do so, we conducted a community-based survey of adults in an area of Tanzania where the burden of stroke is high and growing $[8,20]$.

\section{Materials and Methods}

\section{Study Location}

This study was done in northern Tanzania in the city of Moshi (population 184,289 [21]) and the surrounding rural districts of Hai (population 210,531 [21]) and Moshi Rural (population 466,740 [21]). In 2014, the prevalence of hypertension among adults in Moshi Urban and Moshi Rural districts was 28\%, and the prevalence of diabetes was $6 \%[22,23]$.

\section{Participant Selection}

A 2-stage randomized population-based cluster survey was performed, following World Health Organization recommendations for vaccination coverage cluster surveys [24]. Within the study area, 56 subdistricts were selected randomly in a populationweighted fashion, with selection of urban and rural subdistricts proportionate to their populations. Within each selected subdistrict, 12 point locations were generated randomly using Quantum Geographic Information System (version 2.18.7). The global positioning system coordinates of each selected point were entered into a Garmin eTrex handheld device (Garmin, Olathe, KS, USA), which was used to locate the physical location of each random point. The closest household to the selected point was approached for inclusion in the study; if there was no eligible participant at this household, then the next nearest household was approached. Any adult resident who self-identified as a health-care decision maker for the household was eligible for inclusion.

\section{Survey Translation}

Survey questions were translated into Swahili and back-translated into English. To ensure proper translation of the word "stroke," we piloted several word choices with 15 Tanzanians with both medical and nonmedical backgrounds, who were in unanimous agreement that the appropriate term in Swahili is "kiharusi" but that the English word "stroke" is more widely used and recognized. For this reason, both "kiharusi" and "stroke" were used in all questions regarding stroke to optimize comprehension.

\section{Study Procedures}

Surveys were administered in Swahili by Tanzanian field workers, using Samsung Galaxy Tab A tablets (Samsung, Seoul, Korea). Surveys were designed using Open Data Kit software version 1.12.2 (Seattle, WA, USA). Basic sociodemographic information was collected from all respondents, including age and gender, as well as education of the head of household. Participants were asked to list as many symptoms of a stroke as they could think of. Surveyors did not present participants with a list of options; partici-
Hertz/Madut/William/Maro/Crump/ Rubach 
pants had to name symptoms without prompting. When participants struggled to understand the biomedical concept of "symptoms," surveyors explained this concept but ultimately recorded the participant's response exactly as given. Respondents were subsequently asked "Do you think you have a chance of having a stroke?" Finally, respondents were asked where they would go if they or another adult in their household were to experience a standardized stroke scenario of sudden unilateral paralysis, trouble speaking, trouble walking, confusion, or vision problems. The scenario was adapted from US National Institute for Neurologic Disorders and Stroke (US NINDS) guidelines [25]. This standardized stroke scenario was piloted with local clinicians to ensure that it adequately conveyed a stroke presentation in Tanzania. As a result of this piloting, some symptoms in the US NINDS scenario, such as dizziness and loss of balance or coordination, were eliminated due to concerns that the best Swahili translation of these words would not adequately convey the intended symptom and that "trouble walking" would better convey deficits in balance and coordination in Swahili. In response to the standardized stroke scenario, participants were asked to choose from a pick list of common types of health-care facilities in Tanzania as well as self-treatment at home and traditional healer. The full survey instrument, in both English and Swahili, is provided in the online supplementary material (for all online suppl. material, see www.karger.com/ doi/10.1159/000499069).

\section{Statistical Analyses}

Statistical analyses were performed in RStudio version 3.3.2 (RStudio Inc., Boston, MA, USA). Associations between categorical variables were analyzed with Pearson's chi-square, and continuous variables were analyzed using the Welch 2 sample $t$ test. ORs and corresponding CIs were calculated from contingency tables. A 0.05 cutoff level for statistical significance was used. Urban residence was defined as residence within Moshi Urban District. Conventional stroke symptoms were defined a priori as focal weakness, focal numbness, headache, dizziness, trouble seeing, confusion, or trouble speaking, consistent with the US NINDS guidelines [25]. A socioeconomic status score was derived via principal component analysis [26] from 9 binary variables: post-primary education, presence of electricity in the home, health insurance coverage, home floor material, ownership of a bank account, ownership of a car, ownership of a television, ownership of a refrigerator, and presence of a flush toilet in the home. The minimum sample size was calculated according to WHO guidelines for cluster surveys [24], assuming a proportion (defined as the study area's population that sought health care at a specific health-care facility) of 0.1 , a precision of $10 \%$, a design effect of 1.5 , and an inflation factor of 1.2. The sample size calculation resulted in a minimum of 660 households to be surveyed. Subdistrict population data were taken from the 2012 Tanzania Population and Housing Census [21].

\section{Results}

There were 670 participants, with median (range) age 47 (16-98) years. Of participants, 469 (70.0\%) were females. Table 1 presents the sociodemographic features of survey respondents.

Stroke Perceptions and Care Seeking in Tanzania
Table 1. Sociodemographic features of household survey respondents, Northern Tanzania, $2018(n=670)$

Number of respondents (\%)

Gender, female

$469(70.0)$

Urban residence $154(23.0)$

Education

None

Primary

$494(73.7)$

Secondary

$109(16.3)$

Post-secondary

$40(6.0)$

Have health insurance

$212(31.6)$

Religion

Christian $\quad 547(81.6)$

Muslim

$103(15.4)$

Other

$20(3.0)$

Chagga tribe

$506(75.5)$

Age, years, median (range)

$47.0(16-98)$

Household size, number of persons, median (range)

$3.0(1-12)$

SES score, median (range)

$0.16(0-1.01)$

SES, socioeconomic status.

Table 2. Symptoms of stroke cited by residents of Northern Tanzania, $2018(n=670)$

\begin{tabular}{lc}
\hline Symptom of stroke & $\begin{array}{l}\text { Number of } \\
\text { respondents (\%) }\end{array}$ \\
\hline Don't know any & $407(60.7)$ \\
Focal weakness & $135(20.1)$ \\
Loss of consciousness & $43(6.4)$ \\
Confusion/trouble speaking & $42(6.3)$ \\
Generalized fatigue & $29(4.3)$ \\
Fever & $20(3.0)$ \\
Headache & $18(2.7)$ \\
Dizziness & $17(2.5)$ \\
Palpitations & $15(2.2)$ \\
Arm pain & $10(1.5)$ \\
Jaw pain & $7(1.0)$ \\
Numbness & $7(1.0)$ \\
Shortness of breath & $3(0.4)$ \\
Trouble seeing & $1(0.1)$ \\
Other & $59(8.8)$ \\
\hline
\end{tabular}

\section{Knowledge of Stroke Symptoms}

The symptoms of stroke identified by participants are summarized in Table 2 . The most commonly identified stroke symptom was focal weakness, cited by 135 (20.1\%) respondents. Of participants, $184(27.4 \%)$ were able to identify at least one conventional stroke symptom, 
Table 3. Preferred health-care facility for stroke symptoms among residents of Northern Tanzania, $2018(n=670)$

\begin{tabular}{lc}
\hline Facility & Number of respondents (\%) \\
\hline Hospital & $558(88.3)$ \\
Health center & $57(8.5)$ \\
Dispensary & $49(7.3)$ \\
Don't know & $3(0.4)$ \\
Self-treatment at home & $2(0.3)$ \\
Traditional healer & $1(0.1)$ \\
\hline
\end{tabular}

Table 4. Characteristics of respondents who would present to hospital for stroke symptoms versus those who would not, Northern Tanzania, $2018(n=670)$

\begin{tabular}{lllrr}
\hline & $\begin{array}{l}\text { Hospital } \\
\text { first choice } \\
\text { for stroke } \\
\text { symptoms } \\
(n=558), n(\%)\end{array}$ & $\begin{array}{l}\text { Hospital not } \\
\text { first choice } \\
\text { for stroke } \\
\text { symptoms } \\
(n=112), n(\%)\end{array}$ & OR (95\% CI) & $p$ value \\
& $395(70.8)$ & $74(66.1)$ & $1.25(0.80-1.91)$ & 0.320 \\
\hline Gender, female & $126(22.6)$ & $28(25.0)$ & $0.87(0.55-1.42)$ & 0.579 \\
Urban residence & $131(23.5)$ & $18(16.1)$ & $1.59(0.95-2.82)$ & 0.085 \\
Post-primary education & $176(31.5)$ & $36(32.1)$ & $0.97(0.63-1.51)$ & 0.901 \\
Has health insurance & $428(76.7)$ & $78(69.6)$ & $1.44(0.91-2.24)$ & 0.113 \\
Chagga tribe & $160(28.7)$ & $24(21.4)$ & $1.47(0.91-2.44)$ & 0.117 \\
Knows at least 1 conventional & $42(7.5)$ & $9(8.0)$ & $0.92(0.45-2.08)$ & 0.853 \\
$\quad$ stroke symptom & $47.4(18.9)$ & $51.2(20.3)$ & & 0.073 \\
Perceives self to be at risk of stroke & $0.29(0.31)$ & $0.19(0.21)$ & & $<0.001^{*}$ \\
Age, years, mean (SD) & & & & \\
SES score, mean (SD) & & & & \\
\hline$\quad * p<0.05$. & & & & \\
$\quad$ SES, socioeconomic status. & & & & \\
\hline
\end{tabular}

$33(4.9 \%)$ were able to identify at least 2 conventional symptoms, and $3(0.4 \%)$ were able to identify at least 3 conventional symptoms. The least frequently mentioned conventional stroke symptom was trouble seeing, which was cited by $1(0.1 \%)$ respondent. There was no significant difference in age among those who could identify a conventional stroke symptom versus those who could not (mean age 48.1 vs. 48.0 years, $p=0.957$ ).

\section{Perception of Stroke Risk}

Of respondents, $51(7.6 \%)$ thought they had a chance of having a stroke, whereas 311 (46.4\%) thought they had no chance of having a stroke and 308 (46.0\%) were unsure. Those who perceived themselves to be at risk of a stroke were not significantly older than other respondents (mean age 52.0 vs. 47.7 years, $p=0.082$ ). Females were significantly less likely to perceive themselves to be at risk of stroke than males (6.0 vs. $11.4 \%$, OR $0.49,95 \%$ CI $0.28-0.89, p=0.014$ ).
Health-Care-Seeking Behavior for Stroke Symptoms

The responses to the question "Where would you go if you or another adult in your household experienced sudden unilateral paralysis, trouble speaking, trouble walking, confusion, or trouble seeing?" are summarized in Table 3 . The most commonly selected facility was a hospital, chosen by $558(88.3 \%)$ of participants. No participant stated they would present to a clinic or a pharmacy.

Table 4 compares the characteristics of respondents who stated they would present to a hospital for stroke symptoms versus those who did not. Participants who preferred a hospital had a higher socioeconomic status score than other respondents ( 0.29 vs. $0.19, p<0.001)$. There was otherwise no association between preference for a hospital and age, gender, urban residence, education level, ownership of health insurance, or tribal affiliation. Furthermore, there was no association between preference for hospital and conventional symptom knowledge or perception of self-risk. 


\section{Discussion}

In an area of East Africa with high prevalence of stroke, most residents said they would present to a hospital for stroke symptoms, which is an encouraging finding. However, community knowledge of stroke symptoms was poor, and perception of self-risk was very low. Preference for a hospital was associated with higher socioeconomic status, but not with knowledge of stroke symptoms or perception of self-risk. These findings suggest that knowledge of specific stroke symptoms may not be necessary to recognize that certain symptoms require hospital-level care, and they also suggest that economic considerations may be important drivers of health-care-seeking behavior for stroke.

Only $27 \%$ of respondents could name a conventional stroke symptom, and less than $1 \%$ were able to identify 3 symptoms. These proportions are lower than what has been reported outside of SSA using similarly open-ended questions: in studies from North America, Europe, and Asia, between 51 and $73 \%$ of laypeople could correctly identify at least one stroke symptom without a picklist [27-31]. Community knowledge of stroke symptoms in Tanzania was also lower than what has been reported in West Africa. In Nigeria, for example, $40 \%$ of laypersons could name a stroke symptom without a pick list [12]. For comparison, a table presenting the results of key studies regarding knowledge of stroke symptoms in SSA is included in the online supplementary material. Awareness of certain symptoms, such as trouble seeing, numbness, and dizziness, was especially poor in our study, with fewer than $3 \%$ of respondents identifying these symptoms. Respondents mentioned certain atypical symptoms such as fever or palpitations more often than they mentioned conventional symptoms such as numbness or trouble seeing. Thus, educational interventions to improve stroke knowledge in Tanzania should emphasize symptoms like numbness with low levels of community recognition.

Only $7.6 \%$ of adult respondents thought they had a chance of suffering a stroke, an alarmingly low proportion given the high local prevalence of risk factors and growing prevalence of disease [20, 22, 23]. To our knowledge, only one other study of perceptions of self-risk in SSA has been reported to date, but in that study, over half of adult Ugandans thought they had a chance of having a stroke [17]. The comparatively low levels of perceived self-risk in our study suggest that the need for education regarding the present and growing risk of stroke is particularly acute in Tanzania. Older age was not associated with perception of self-risk, and females were significant-

Stroke Perceptions and Care Seeking in Tanzania ly less likely to consider themselves at risk of stroke in our study, suggesting that educational interventions should be targeted to elderly and female populations.

Despite low levels of symptom knowledge and selfperception of risk, a large majority of respondents stated they would present to a hospital for stroke-like symptoms. Preference for a hospital is important in Tanzania because other facilities typically do not have access to the necessary diagnostic modalities such as computed tomography or treatments such as thrombolytics and physical rehabilitation. The large proportion of participants who would present to a hospital for stroke symptoms is encouraging. However, it remains unknown whether prompt presentation to a hospital for stroke in SSA results in improved outcomes. Although early presentation and treatment in high-income countries are associated with better long-term neurologic outcomes [19], the benefit of presentation to a hospital is unknown in SSA, where delays in health-care seeking are common and use of thrombolytics for stroke is rare [32, 33].

Knowledge of symptoms and perception of self-risk were not associated with preference for a hospital for a scenario of stroke symptoms. The relationship between stroke symptom awareness and health-care-seeking behavior worldwide is heterogenous. Better symptom knowledge was associated with appropriate care seeking in a handful of studies performed in Asia [34-36], whereas most studies performed in Europe and North America have found no such association [37-40]. Our study also found no such association, suggesting that educational programming regarding stroke symptoms may not have an impact on health-care utilization. To our knowledge, this is the first study to examine the relationship between stroke symptom awareness and health-care-seeking behavior in SSA, and additional research is needed to aid in formulation of effective public health interventions to increase rapid hospital presentation for strokes. On bivariable analysis, the only predictor of preference for a hospital for stroke symptoms was higher socioeconomic status, although this association may be due to unmeasured confounders. This finding is consistent with the results of a study in Zimbabwe which found that patients with delayed hospital presentation for stroke reported more difficulty affording care [32]. Together, these findings suggest that reduction of financial barriers to stroke care in SSA might result in prompter presentation to hospitals.

This study had several limitations. First, only self-identified health-care decision makers were eligible for study participation, in order to survey those whose opinions drive actual health-care utilization. Thus, the study sample 
may not have been representative of Tanzanian adults as a whole. Furthermore, because this study was performed during daytime hours in the home, males and those with occupations outside the home were likely underrepresented in the study sample. Additionally, social desirability bias may have pushed some respondents to report that they would present to a hospital for stroke symptoms if they perceived this to be the most acceptable answer; therefore, the true proportion of adults presenting to a hospital for stroke may be lower than what is reported here. Moreover, participants were not asked to report how quickly they would present to their preferred facility for stroke symptoms. Collecting such information would have allowed for an assessment of presentation delays, another important consideration in stroke care-seeking behavior. Furthermore, we did not assess participants' awareness of stroke causes or sources of knowledge regarding stroke in this study. Obtaining this information in future studies would be beneficial in the design of community educational interventions regarding stroke. Finally, information about individual respondents' stroke risk profiles was not collected which would have allowed for a more nuanced analysis of determinants of stroke knowledge, perception of risk, and health-care seeking behavior. Nonetheless, given the known high local burden of risk factors such as hypertension, the low proportion of respondents in this study who knew a conventional stroke symptom or perceived themselves to be at risk of stroke, and the lack of association between age and stroke symptom knowledge or perception of self-risk in our study, there is clearly a need for community stroke education in northern Tanzania.

\section{Conclusions} risk of stroke are low in northern Tanzania, but the majority of adults would present to a hospital for stroke-like symptoms. There is an urgent need for community eduand SSA at large. Mariam Kabongo, Hyasinta Massawe, Pili Shekolowa, and Zanuni Kweka.

\section{Statement of Ethics}

This study received ethics approval from the Duke Health Institutional Review Board, the Kilimanjaro Christian Medical Centre Research Ethics Committee, and the Tanzania National Institutes for Medical Research Ethics Coordinating Committee. All respondents provided written informed consent prior to participation in the survey.

\section{Disclosure Statement}

The authors have no conflicts of interest to declare.

\section{Funding Sources}

This study was funded by the Bill and Melinda Gates Foundation (grant no. OPP1158210). J.T.H. and D.B.M. received support from US National Institutes of Health Fogarty International Center grant D43TW009337; J.A.C. from US National Institutes of Health National Institute of Allergy and Infectious Diseases grant R01AI121378; and M.P.R. from US National Institutes of Health National Institute of Allergy and Infectious Diseases grant K23AI116869. Funders were not involved in the preparation of the data or the manuscript in any way.

\section{Author Contributions}

J.T.H., J.A.C., and M.P.R.: conceived the study; D.B.M., J.A.C., V.P.M., and M.P.R.: designed the study protocol; D.B.M., G.W., and M.P.R.: implemented and supervised the survey; J.T.H.: performed the data analysis and drafted the manuscript; D.B.M., G.W., V.P.M., J.A.C., and M.P.R.: critically revised the manuscript for critical content. All authors read and approved of the final manuscript.

Knowledge of stroke symptoms and perception of selfcation interventions regarding stroke in northern Tanzania, and additional research is needed to examine the barriers to prompt hospital-based stroke care in Tanzania

\section{Acknowledgments}

The authors would like to thank the members of the Healthcare Utilization Survey team who performed the survey: Timothy Peter,

References

46
Neuroepidemiology 2019;53:41-47 DOI: $10.1159 / 000499069$
Hertz/Madut/William/Maro/Crump/ Rubach
1 Naghavi M, Abajobir AA, Abbafati C, Abbas KM, Abd-Allah F, Abera SF, et al.; GBD 2016 Causes of Death Collaborators. Global, regional, and national age-sex specific mortality for 264 causes of death, 1980-2016: a systematic analysis for the Global Burden of Disease Study 2016. Lancet. 2017 Sep;390(10100):1151-210.

2 Feigin VL, Forouzanfar MH, Krishnamurthi R, Mensah GA, Connor M, Bennett DA, et al.; Global Burden of Diseases, Injuries, and Risk Factors Study 2010 (GBD 2010) and the GBD Stroke Experts Group. Global and regional burden of stroke during 1990-2010: findings from the Global Burden of Disease Study 2010. Lancet. 2014 Jan;383(9913):245-54.

3 Lekoubou A, Nkoke C, Dzudie A, Kengne AP. Stroke admission and case-fatality in an urban medical unit in sub-Saharan Africa: a fourteen year trend study from 1999 to 2012 . J Neurol Sci. 2015 Mar;350(1-2):24-32.

6


4 Sarfo FS, Akassi J, Awuah D, Adamu S, Nkyi C, Owolabi M, et al. Trends in stroke admission and mortality rates from 1983 to 2013 in central Ghana. J Neurol Sci. 2015 Oct;357(12):240-5.

5 Owolabi MO, Akarolo-Anthony S, Akinyemi R, Arnett D, Gebregziabher M, Jenkins C, et al.; Members of the H3Africa Consortium. The burden of stroke in Africa: a glance at the present and a glimpse into the future. Cardiovasc J Afr. 2015 Mar-Apr;26(2 Suppl 1):S27-38.

6 Adeloye D. An estimate of the incidence and prevalence of stroke in Africa: a systematic review and meta-analysis. PLoS One. 2014 Jun; 9(6):e100724

7 Thrift AG, Cadilhac DA, Thayabaranathan T, Howard G, Howard VJ, Rothwell PM, Donnan GA. Global stroke statistics. Int J Stroke. 2014 Jan;9(1):6-18.

8 Walker R, Whiting D, Unwin N, Mugusi F, Swai M, Aris E, et al. Stroke incidence in rural and urban Tanzania: a prospective, community-based study. Lancet Neurol. 2010 Aug; 9(8):786-92.

9 Cossi MJ, Preux PM, Chabriat H, Gobron C, Houinato D. Knowledge of stroke among an urban population in Cotonou (Benin). Neuroepidemiology. 2012;38(3):172-8.

10 Donkor ES, Owolabi MO, Bampoh P, Aspelund T, Gudnason V. Community awareness of stroke in Accra, Ghana. BMC Public Health. 2014 Feb;14(1):196.

11 Akinyemi RO, Ogah OS, Ogundipe RF, Oyesola OA, Oyadoke AA, Ogunlana MO, et al. Knowledge and perception of stroke amongst hospital workers in an African community. Eur J Neurol. 2009 Sep;16(9):998-1003.

12 Wahab KW, Okokhere PO, Ugheoke AJ, Oziegbe O, Asalu AF, Salami TA. Awareness of warning signs among suburban Nigerians at high risk for stroke is poor: a cross-sectional study. BMC Neurol. 2008 May;8(1):18.

13 Obembe AO, Olaogun MO, Bamikole AA, Komolafe MA, Odetunde MO. Awareness of risk factors and warning signs of stroke in a Nigeria university. J Stroke Cerebrovasc Dis. 2014 Apr;23(4):749-58.

14 Komolafe MA, Obembe AO, Olaogun MO, Adebiyi AM, Ugalahi T, Dada O, Kanu A, Adebiyi OC, Akilo F, Ogunkoya B, Fawale B. Awareness of stroke risk factors and warning signs in Nigerian adolescents compared with adults. J Stroke Cerebrovasc Dis. 2015 Mar 24(3):687-93

15 Nansseu JR, Atangana CP, Petnga SN, Kamtchum-Tatuene J, Noubiap JJ. Assessment of the general public's knowledge of stroke: A cross-sectional study in Yaoundé, Cameroon. J Neurol Sci. 2017 Jul;378:123-9.

16 Arisegi SA, Awosan KJ, Oche MO, Sabir AA, Ibrahim MT. Knowledge and practices relat- ed to stroke prevention among hypertensive and diabetic patients attending Specialist Hospital, Sokoto, Nigeria. Pan Afr Med J. 2018 Jan;29:63.

17 Nakibuuka J, Sajatovic M, Katabira E, Ddumba E, Byakika-Tusiime J, Furlan AJ. Knowledge and Perception of Stroke: A Population-Based Survey in Uganda. ISRN Stroke. 2014;2014.

18 Kaddumukasa M, Kayima J, Kaddumukasa MN, Ddumba E, Mugenyi L, Pundik S, et al. Knowledge, attitudes and perceptions of stroke: a cross-sectional survey in rural and urban Uganda. BMC Res Notes. 2015 Dec; 8(1):819.

19 Emberson J, Lees KR, Lyden P, Blackwell L, Albers G, Bluhmki E, et al.; Stroke Thrombolysis Trialists' Collaborative Group. Effect of treatment delay, age, and stroke severity on the effects of intravenous thrombolysis with alteplase for acute ischaemic stroke: a metaanalysis of individual patient data from randomised trials. Lancet. 2014 Nov;384(9958): 1929-35.

20 Walker RW, Viney R, Green L, Mawanswila $\mathrm{M}$, Maro VP, Gjertsen C, et al. Trends in stroke admissions to a Tanzanian hospital over four decades: a retrospective audit. Trop Med Int Health. 2015 Oct;20(10):1290-6.

21 Population and Housing Census. Population Distribution by Administrative Areas. Dar es Salaam: Tanzania National Bureau of Statistics; 2013.

22 Galson SW, Staton CA, Karia F, Kilonzo K, Lunyera J, Patel UD, et al. Epidemiology of hypertension in Northern Tanzania: a community-based mixed-methods study. BMJ Open. 2017 Nov;7(11):e018829.

23 Stanifer JW, Cleland CR, Makuka GJ, Egger JR, Maro V, Maro H, et al. Prevalence, Risk Factors, and Complications of Diabetes in the Kilimanjaro Region: A Population-Based Study from Tanzania. PLoS One. 2016 Oct; 11(10):e0164428.

24 WHO. World Health Organization Vaccination Coverage Cluster Surveys: Reference Manual. Geneva: World Health Organization; 2018.

25 NINDS. Know Stroke: Know the Signs, Act in Time. Bethesda (MD): US National Institutes of Health; 2013.

26 Vyas S, Kumaranayake L. Constructing socioeconomic status indices: how to use principal components analysis. Health Policy Plan. 2006 Nov;21(6):459-68.

27 Gill R, Chow CM. Knowledge of heart disease and stroke among cardiology inpatients and outpatients in a Canadian inner-city urban hospital. Can J Cardiol. 2010 Dec;26(10): $537-40$.

28 Ramirez-Moreno JM, Alonso-Gonzalez R, Peral-Pacheco D, Millan-Nunez MV, Agu-
irre-Sanchez JJ. Stroke Awareness Is Worse among the Old and Poorly Educated: A Population-Based Survey. J Stroke Cerebrovasc Dis. 2015 May;24(5):1038-46.

29 Al Shafaee MA, Ganguly SS, Al Asmi AR. Perception of stroke and knowledge of potential risk factors among Omani patients at increased risk for stroke. BMC Neurol. 2006 Oct; $6(1): 38$.

30 Cheung RT, Li LS, Mak W, Tsang KL, Lauder IJ, Chan KH, et al. Knowledge of stroke in Hong Kong Chinese. Cerebrovasc Dis. 1999 Mar-Apr;9(2):119-23.

31 Kim JS, Yoon SS. Perspectives of stroke in persons living in Seoul, South Korea. A survey of 1000 subjects. Stroke. 1997 Jun;28(6): $1165-9$.

32 Seremwe F, Kaseke F, Chikwanha TM, Chikwasha V. Factors associated with hospital arrival time after the onset of stroke symptoms: A cross-sectional study at two teaching hospitals in Harare, Zimbabwe. Malawi Med J. 2017 Jun;29(2):171-6.

33 Bryer A, Wasserman S. Thrombolysis for acute ischemic stroke in South Africa. Int J Stroke. 2013 Oct; 8 Suppl A100:112-3.

34 Yang J, Zheng M, Cheng S, Ou S, Zhang J, Wang N, Cao Y, Wang J. Knowledge of stroke symptoms and treatment among community residents in Western Urban China. J Stroke Cerebrovasc Dis. 2014 May-Jun;23(5):121624.

35 Kim YS, Park SS, Bae HJ, Cho AH, Cho YJ, Han MK, et al. Stroke awareness decreases prehospital delay after acute ischemic stroke in Korea. BMC Neurol. 2011 Jan;11(1):2.

36 Koksal EK, Gazioglu S, Boz C, Can G, Alioglu Z. Factors associated with early hospital arrival in acute ischemic stroke patients. Neurol Sci. 2014 Oct;35(10):1567-72

37 Moreira E, Correia M, Magalhães R, Silva MC. Stroke awareness in urban and rural populations from northern Portugal: knowledge and action are independent. Neuroepidemiology. 2011;36(4):265-73.

38 Ritter MA, Brach S, Rogalewski A, Dittrich R, Dziewas R, Weltermann B, et al. Discrepancy between theoretical knowledge and real action in acute stroke: self-assessment as an important predictor of time to admission. Neurol Res. 2007 Jul;29(5):476-9.

39 Zock E, Kerkhoff H, Kleyweg RP, van BavelTa TB, Scott S, Kruyt ND, et al. Help seeking behavior and onset-to-alarm time in patients with acute stroke: sub-study of the preventive antibiotics in stroke study. BMC Neurol. 2016 Nov; 16(1):241.

40 Teuschl Y, Brainin M. Stroke education: discrepancies among factors influencing prehospital delay and stroke knowledge. Int $J$ Stroke. 2010 Jun;5(3):187-208. 